\title{
Synthesis and Stereochemical Properties of Chiral Square Complexes of Iron(II)
}

\author{
Thomas Bark, ${ }^{[a]}$ Alexander von Zelewsky, ${ }^{[a],{ }^{*}}$ Dmitrij Rappoport, ${ }^{[b]}$ Markus Neuburger, ${ }^{[c]}$ \\ Silvia Schaffner, ${ }^{[c]} \quad$ Jérôme Lacour, ${ }^{[\mathrm{d}]} \quad$ Jonathan Jodry ${ }^{[\mathrm{d}]}$
}

23rd April 2004

\begin{abstract}
The hexadentate, and ditopic ligand 2,5bis([2,2']bipyridin-6-yl)pyrazine yields a chiral, tetrameric, square shaped, self-assembled species upon complexation with $\mathrm{Fe}^{2+}$-ions. The racemate of this complex was resolved with antimonyl tatrate as chiral auxiliary. The purity of the enantiomer was determined by NMR spectroscopy, using a chiral, diamagnetic shift reagent, as well as by circular dichroism (CD). The CD-spectrum was also calculated by time dependent density functional theory, and the correlation that was found between $\mathrm{CD}$ spectrum and configuration was confirmed by X-ray cristallography.

When a "chiralised" version of the ligand was used instead, the corresponding iron complex was obtained in diastereomerically pure form.
\end{abstract}

\footnotetext{
a] Prof. A. von Zelewsky, Thomas Bark Department of Chemistry

University of Fribourg

Pérolles

CH-1700 Fribourg

Switzerland

Fax: +41-26-3009738

E-mail: alexander.vonzelewsky@unifr.ch

[b] Dmitrij Rappoport

Institute of Physical Chemistry

Technical University of Karlsruhe

Fritz-Haber-Weg 4, building 30.34

D-76131 Karlsruhe

Germany

${ }^{[c]}$ Markus Neuburger, Silvia Schaffner

Laboratory for Chemical Crystallography

University of Basel

Spitalstrasse 51

CH-4056 Basel

Switzerland

[d] Jérôme Lacour, Jonathan Jodry

Department of Organic Chemistry

University of Geneva

Quai Ernest Ansermet 30

CH-1211 Genève

Switzerland
}

\section{Abstract in German}

Der hexadentate und ditopische Ligand 2,5Bis([2,2']bipyridin-6-yl)pyrazin bildet bei der Selbstorganisationsreaktion mit $\mathrm{Fe}^{2+}$-Ionen einen chiralen, quadratförmigen Tetramerkomplex. Das Racemat dieses Komplexes wurde mit Hilfe von Antimonyltartrat in die Enantiomere getrennt. Die Reinheit des Enantiomers wurde durch NMR-Spektroskopie unter Zuhilfenahme eines chiralen, diamagnetischen Shift-Reagenzes untersucht, wie auch duch die Beobachtung des Circulardichroismus (CD). Das CD-Spektrum wurde zudem mit zeitabhängiger Dichtefunktionaltheorie berechnet, wobei die vorhergesagte Korrelation zwischen CDSpektrum und Konfiguration des Komplexes durch Röntgenstrukturanalyse bestätigt wurde.

Die Verwendung einer "chiralisierten" Variante des Liganden ergab den entsprechenden Eisenkomplex in diastereomerenreiner Form.

Keywords Chiral resolution, diastereoselectivity, Iron, molecular square, self assembly, TDDFT.

\section{Introduction}

On the vast playground of co-ordination chemistry-based self assembly reactions, one particularly prominent class of compounds are the so-called molecular squares. This terme denotes a variety of complexes, which have in common an arrangement of four metal ions or metal fragments in the corners of a square, connected through organic ligand strands. The ligands may co-ordinate through one donor atom, as e.g. in the platinum or palladiumbased complexes developed by Fujita. ${ }^{[1][2]}$ If the ligands 
co-ordinate by two or three donor atoms to each metal, chiral centres ${ }^{1}$ are created. Even so the metals represent centres of chirality, the entire complex can be achiral, if the arrangement of ligand strands is grid-like (type A, fig. 1). Examples are the complexes from tetrahedrally co-ordinated metal centres presented by the Osborn group, ${ }^{[5]}$ as well as the related grids from the laboratories of Lehn, ${ }^{[6]}$ besides others. ${ }^{[7][8][9][10][11]}$ (For the exception of a chiral complex of type $\mathbf{A}$, see Bassani et al. ${ }^{[12]}$ ).

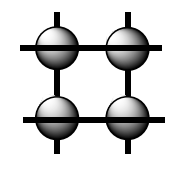

A
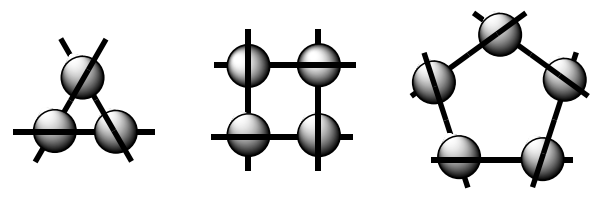

$\vec{\Delta}$
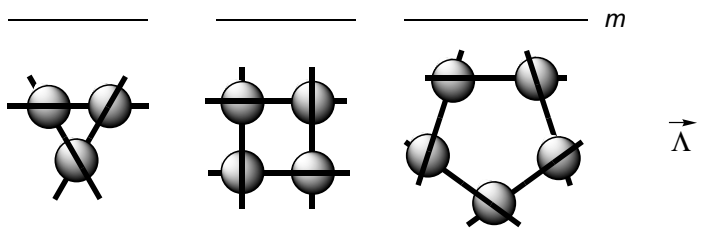

B

C rameric complexes with zinc(II) and no anchillary ligands are found in these complexes. ${ }^{16]}$ Whereas the complex $\left[\mathrm{Zn}_{4} \mathbf{L 1}_{4}\right]\left(\mathrm{PF}_{6}\right)_{8}$ was obtained as racemic compound, "chiralised" ligand L2 showed high diastereoselectivity and yielded $\left[\mathrm{Zn}_{4} \mathbf{L} \mathbf{2}_{4}\right]\left(\mathrm{PF}_{6}\right)_{8}$ with $90 \%$ d.e. (The use of terpene-derivatised ligands for the predetermination of the configuration of chiral metal centres is a well established method. ${ }^{[17]}$ ) These ligands that yield chiral, inter-

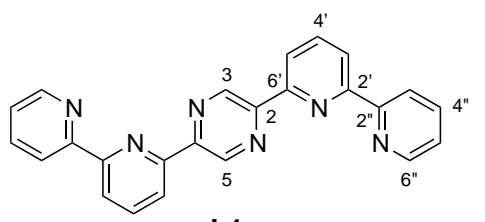

L1

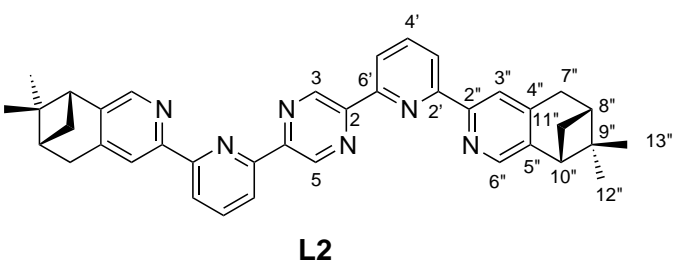

Figure 2: Ligands $\mathbf{L} \mathbf{1}$ and $\mathbf{L 2}$

Figure 1: Schematic representation of several types of supramolecular complexes. The members of the second group $(\mathbf{B}, \mathbf{C}$ and $\mathbf{D})$ are chiral.

If the four ligand strands "wrap" the four metal ions in an interwoven fashion, the resulting molecular square is a chiral complex (type C, fig. 1). The group of Dunbar published the first example, a nickel complex with the bis-didentate ligand 3,6-di-2-pyridyl-1,2,4,6-tetrazine. ${ }^{\text {[13] }}$ $\mathrm{Bu}$ and coworkers followed with the corresponding zinc compound, which resolves spontaneously into single enantiomers upon crystallisation. ${ }^{[14]}$ However, it was not possible for them to obtain larger amounts of enantiomerically pure complex in order to investigate its stereochemical properties. This might be due to the kinetic instability of the zinc complex. The tetrazine ligand does not occupy all all co-ordination sites of the metal ions: in both cases, two solvent molecules per metal ion are needed to complete the quasi-octahedral co-ordination sphere. Our group has designed ligands that provide two terdentate, terpyridine-type binding domains (fig. 2), i.e. 2,5-bis([2,2']bipyridin-6-yl)pyrazine $\mathbf{L} 1$ and chiral derivatives of it.[15] These ligands were shown to yield tet-

\footnotetext{
${ }^{1}$ As chirality descriptors, we use the "Oriented Line Reference System".[3][4]
}

\section{Discussion of Results}

Complex synthesis Although the related zinc complexes that we reported recently formed spontaneously upon combination of a zinc source, such as the perchlorate or fluoroborate, with the ligands (L1 or L2) in the aprotic, co-ordinating solvent $\mathrm{MeCN}$, the corresponding iron(II) complexes could not be obtained in this way. Particularly $\mathbf{L} \mathbf{1}$ yielded insoluble co-ordination polymers when reacted with ferrous salts. We suspected these polymers to be kinetic intermediates, but even prolonged heating of this insoluble material in $\mathrm{PhCN}$ at reflux temperature failed to convert them into the discrete, tetrameric complex. Therefore it was surprising 
to discover that the squares can be readily synthesised applying microwave heating: Stoichiometric amounts of $\left[\mathrm{Fe}\left(\mathrm{H}_{2} \mathrm{O}\right)_{6}\right]\left(\mathrm{BF}_{4}\right)_{2}$ and $\mathbf{L 1}$ were heated in $9 / 1$ ethylene glycol/water for four minutes to reflux to furnish the desired complex $\left[\mathrm{Fe}_{4} \mathbf{L 1}_{4}\right]\left(\mathrm{PF}_{6}\right)_{8}$ in quasi-quantitative yield after precipitation as hexafluorophosphate.

The dark green compound is diamagnetic and kinetically stable. Its NMR-spectrum displays only 8 signals, i.e. half of all 16 ligand protons. This fact underlines the $D_{4^{-}}$ symmetry of the complex, where 2 of the 4 lateral $C_{2}$-axes devide each ligand into two equivalent halfes. A detailed analysis of the shifts, that proton resonances of the ligand undergo upon complexation confirms the circular structure of the complex (fig. 3): the proton $\mathrm{H}-\mathrm{C}(3 / 5)$ as well as proton $\mathrm{H}-\mathrm{C}(6 ")$ are subject to considerable up-field shifts of $\Delta \delta=-2.82 \mathrm{ppm}$ and $\Delta \delta=-1.69 \mathrm{ppm}$, respectively. These shifts are due to the exposure of these protons to the magnet field provoked by the ring current of adjacent ligand molecules. The ring-shaped architecture of the complex becomes more evident when regarding the $m$-protons of the inner pyridine ring, $\mathrm{H}-$ $\mathrm{C}\left(3^{\prime}\right)$ and $\mathrm{H}-\mathrm{C}\left(5^{\prime}\right)$ : These protons are chemically very similar and are hardly distinguished in the NMR spectrum of the free ligand. Compared to this, they behave differently within the complex: $\mathrm{H}-\mathrm{C}\left(5^{\prime}\right)$ appears at lower field $(\Delta \delta=-0.29 \mathrm{ppm})$, as it points towards a neighbouring ligand fragment. On the other hand, $\mathrm{H}-$ $\mathrm{C}\left(3^{\prime}\right)$, which points outside the complex, is shifted upfield $(\Delta \delta=+0.45 \mathrm{ppm})$, as expected, due to the decrease of electron density in the complexed ligand.

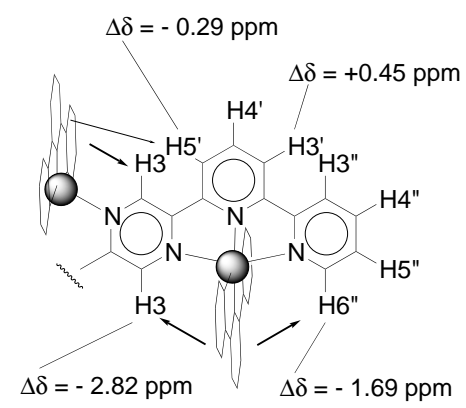

Figure 3: A fragment of the complex cation $\left[\mathrm{Fe}_{4} \mathbf{L} \mathbf{1}_{4}\right]^{8+}$ : Change in ${ }^{1} \mathrm{H}-\mathrm{NMR}$-shifts of the ligand $\mathbf{L} \mathbf{1}$ upon complexation to $\mathrm{Fe}^{2+}$

The nuclearity of this circular assembly cannot be elucidated directly from the NMR-spectrum, but electrospray ionisation mass spectrometry (ESI-MS) gave an answer to this question: (fig. 4) Only tetrameric fragments of the type $\left\{\left[\mathrm{Fe}_{4} \mathbf{L 1}_{4}\right]\left(\mathrm{PF}_{6}\right)_{n}\right\}^{8-n}$ with $n=2 \ldots 6$ are found in MeCN-solution. Neither ESI-MS, nor NMR indicated the presence of a second, trimeric species; such a trimer was found to be a minor equilibrium product of the cor- responding zinc(II) complex.

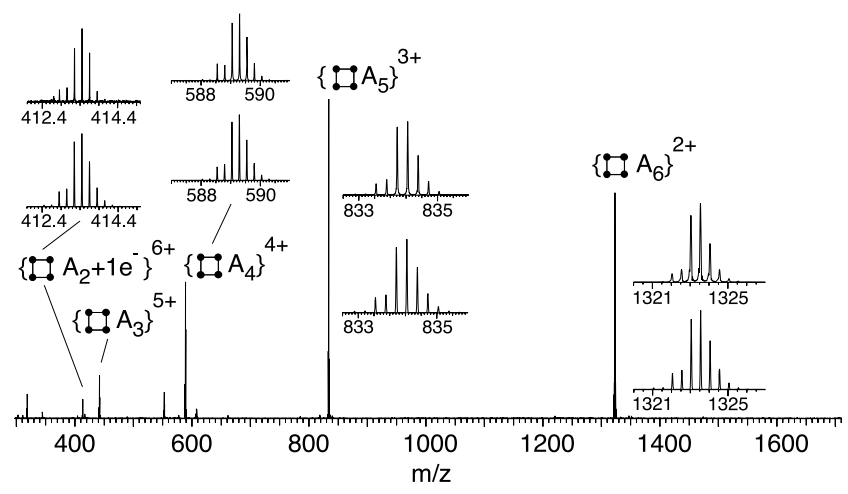

Figure 4: ESI mass spectrum of $\left[\mathrm{Fe}_{4} \mathbf{L 1}_{4}\right]\left(\mathrm{PF}_{6}\right)_{8}$. The continuous loss of $\mathrm{PF}_{6}^{-}$anions leads to series of fragments. Insets: Found (top) and calculated (bottom) isotopic distribution patterns.

Resolution of the complex and stereochemical properties As we have already stated in the introduction, complexes of the type of $\left[\mathrm{Fe}_{4} \mathbf{L 1}_{4}\right]\left(\mathrm{PF}_{6}\right)_{8}$ are chiral, due to the interwoven arrangement of the ligand strands. All iron(II)-ions are chiral-at-metal and have the same configuration within one complex cation. The entire complex ion can also be regarded as a short, quadruple stranded helix. This helix is of $P$-helicity, if the configuration of the metal ions is $\vec{\Lambda}$.

The complex is obtained as a racemate, evidently. It was separated by preferential crystallisation of diastereomeric salts, using enantiomerically pure "antimonyl tartrate" $\left(2 R, 2^{`} R, 3 R, 3^{\circ} R\right)-\left[\mathrm{Sb}_{2} \mathrm{tart}_{2}\right]^{2-}$ as resolving agent. As the fluorophosphate of the complex is not soluble in water, the complex was transformed into the readily soluble chlorideby simple metathesis reaction of $\left[\mathrm{Fe}_{4} \mathbf{L}_{4}\right]\left(\mathrm{PF}_{6}\right)_{8}$ with $\mathrm{NBu}_{4} \mathrm{Cl}$ in nitromethane, as $\left[\mathrm{Fe}_{4} \mathbf{L} \mathbf{1}_{4}\right] \mathrm{Cl}_{8}$ is insoluble in this solvent. Therefore it precipitates and can be isolated by filtration. ${ }^{2}$ The chloride is, then, dissolved in water and potassium antimonyl tartrate is added. In cases when the resolution was successful, one obtains brick-shaped crystals of up to $1 \mathrm{~mm}$ size. Unfortunately, this crystallisation is very delicate, and in most cases, we obtained an amorphous powder, that contained both enantiomers of the complex cation. If seeding crystals are available from one successful run, the crystallisation becomes straightforward. X-Ray crystallography revealed the chemical composition of the crystalline material to be $(\vec{\Lambda}, \vec{\Lambda}, \vec{\Lambda}, \vec{\Lambda})$ $\left[\mathrm{Fe}_{4} \mathbf{L} \mathbf{1}_{4}\right] \mathrm{Cl}_{2}\left[\mathrm{Sb}_{2} \text { tart }_{2}\right]_{3}$; the details of the structure will

\footnotetext{
${ }^{2}$ It is noteworth to state that this product could not be obtained by the reaction of $\mathrm{FeCl}_{2}$ with $\mathbf{L} \mathbf{1}$.
} 
be discussed in the following paragraph. These crystals were then dissolved in water and the complex was again precipitated as the hexafluorophosphate salt.

The resolved complex was investigated by UV-Vis-, CDand NMR-spectroscopy. The optical absorption spec-

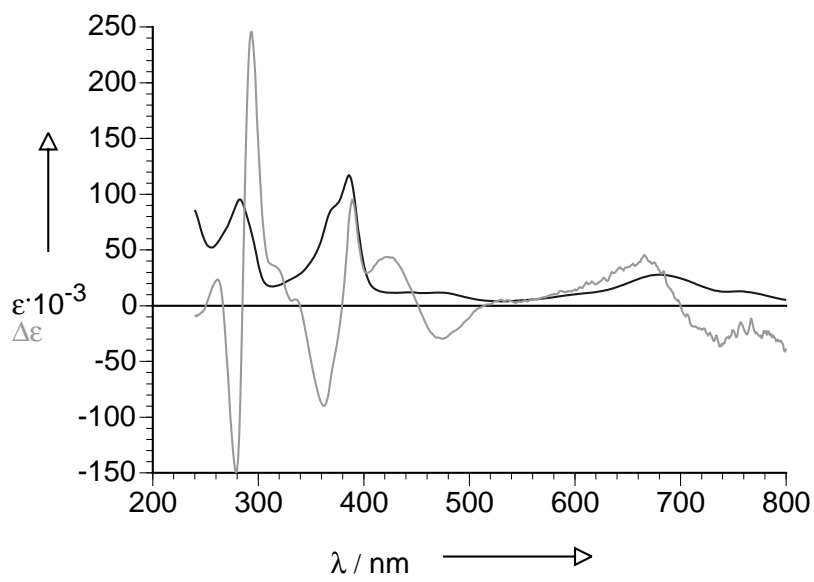

Figure 5: Optical properties of $\left(\vec{\Lambda}_{4}\right)-\left[\mathrm{Fe}_{4} \mathbf{L 1}_{4}\right]\left(\mathrm{PF}_{6}\right)$. Black: UV-Vis-, Grey: CD-spectrum.

tra shows two bands at 283 and $386 \mathrm{~nm}$, respectively, which are due to ligand centred transitions, as well as a strong MLCT band at around $680 \mathrm{~nm}(\epsilon=6.98$. $10^{3} \mathrm{l} \mathrm{mol}^{-1} \mathrm{~cm}^{-1}$ per $\left.\mathrm{Fe}^{2+}\right)$. All these bands show strong CD-activities. The most prominent effect is the exciton coupling of the $283 \mathrm{~nm}$-transition, which has a positive sign (i.e. the Cotton effect (CE) at longer wavelengths is positive, whereas the short wave $\mathrm{CE}$ is negative and also has a smaller amplitude than the long wave CE). From this results we could not directly deduce the configuration of the complex: In contrast to the $\left[\mathrm{M}(\mathrm{bpy})_{3}\right]^{\mathrm{n}+}$-case, for which experimental and theoretical investigations of the CD activity are numerous in the literature, ${ }^{[21]}$ we did not find any report about the correlation of $\left[\mathrm{M}(\text { terpy* })_{2}\right]^{\mathrm{n}+}$ type complexes and their CD-spectra $\left(\right.$ terpy ${ }^{*}=$ an asymmetrical $2,2^{6}: 6^{6}, 2^{\text {" }}$-terpyridine). Thus the necessity of an $\mathrm{X}$-ray analysis and the computational simulation of the CD-spectrum.

We also investigated the influence of the chiral, diamagnetic, anionic shift reagent $\Delta$-TRISPHAT ${ }^{[22, ?]}$ (fig. 6) onto the racemic, as well as onto the resolved complex. 4.4 mole TRISPHAT are added per mole of complex cation, which is dissolved in $\left[\mathrm{D}_{3}\right] \mathrm{MeCN}$. Although signals for the two enantiomers of the complex cation are only poorly separated, as the induced shifts are relatively small (smaller than the line splitting of the signals), the enantiomeric purity of the resolved complex becomes evident (fig. 7).

The resolved complex is kinetically very stable. In dilute MeCN solutions, we observed a decrease of CD activity only at elevated temperature $\left(60^{\circ} \mathrm{C}\right)$ over the course of<smiles>CC(C)[NH3+]</smiles>

Figure 6: $(\Delta)-\mathrm{NBu}_{4}$ TRISPHAT

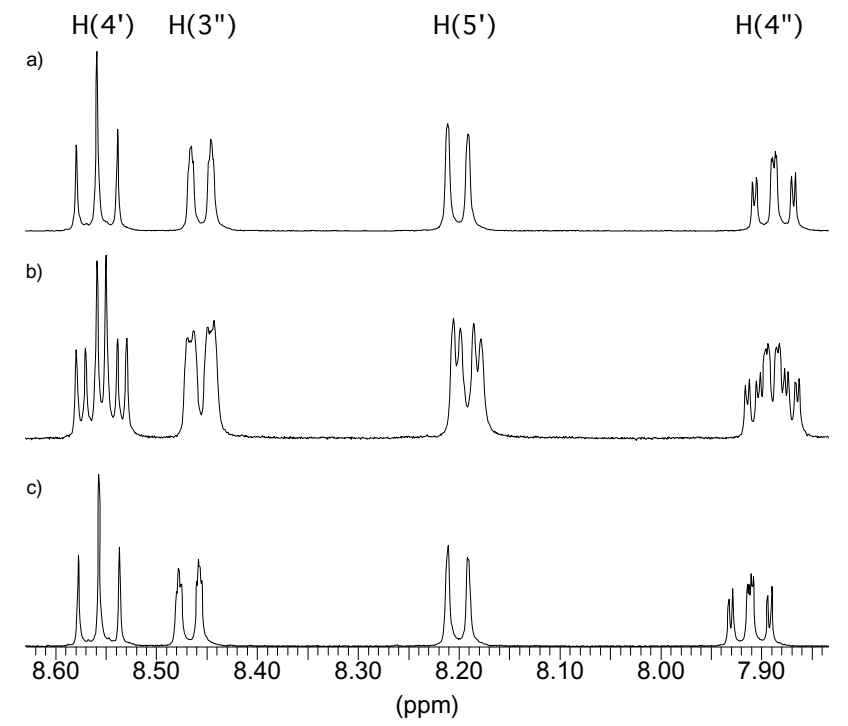

Figure 7: A part of the ${ }^{1} \mathrm{H}-\mathrm{NMR}$-spectrum of $\left[\mathrm{Fe}_{4} \mathbf{L 1}_{4}\right]\left(\mathrm{PF}_{6}\right)_{8}$ in $\left[\mathrm{D}_{3}\right]-\mathrm{MeCN}$

a) The racemic complex without additive

b) The racemic complex with $\Delta$-TRISPHAT

c) The resolved complex with $\Delta$-TRISPHAT

several weeks. This decay is irregular and does not follow a first order reaction kinetic, as it would be expected for a simple racemisation. Deterioration of the UV-Vis spectrum, as well as MS indicated that rather a decomposition took place and $\left[\mathrm{Fe} \mathbf{L} \mathbf{1}_{2}\right]^{2+}$ was mainly formed.

Crystal structure of $\left[\mathrm{Fe}_{4} \mathbf{L 1}_{4}\right] \mathrm{Cl}_{2}\left[\mathrm{Sb}_{2} \text { tart }_{2}\right]_{3}$ As mentioned, crystals of the antimonyl tartrate were submitted to an X-ray crystal structure analysis, in order to confirm the structure of the complex, and more important, in order to establish the configuration of the crystallised enantiomer of the complex cation. The compound crystallises in the non-centrosymmetric space group $P 2_{1}$. The asymmetric unit contains an entire $\left[\mathrm{Fe}_{4} \mathbf{L} \mathbf{1}_{4}\right]^{8+}$-cation as well as three dimeric antimonyltartrate complex anions ${ }^{[24][25]}$ 
and two chloride ions. One of the chloride ions occupies a position in the centre of the molecular square (fig. 8, 9). Per complex cation, we find at least 54(!) watermolecules; the exact number of which could not be determined exactly by cristallography due to the size and extreme water content of the compound. The water molecules and the antimonyl tartrate anions form an infinite network through hydrogen bonds (not shown). The complex cation displayed the expected interwoven arrangement of ligand strands.

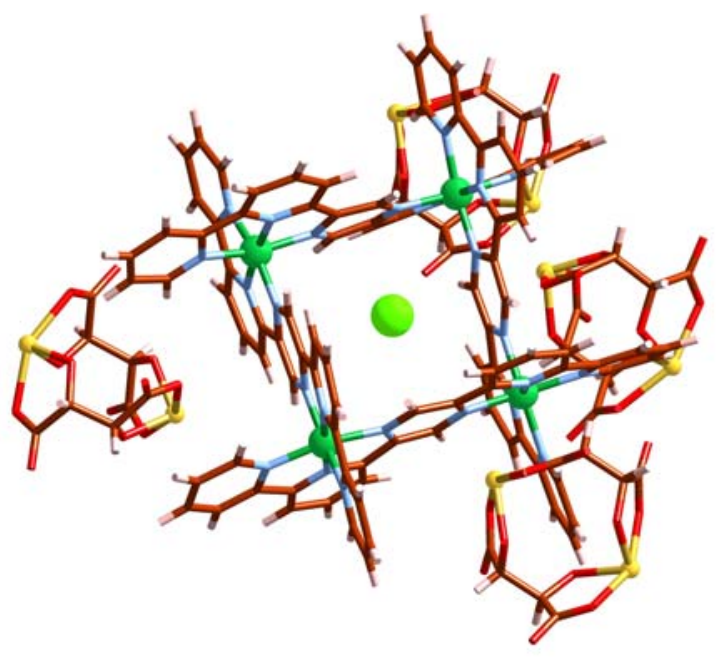

Figure 8: Top-view onto the complex cation, alltogether with four antimonyl tartrate double helices. C: brown, N: blue, O: red, $\mathrm{Cl}$ : green, Fe: mint, $\mathrm{Sb}$ : yellow.

The co-ordination environments of the the four cristallographically independent iron(II)-ions are in the expected range: The co-ordination geometry is a slightly distorted octahedron. The bond lenghts for the sixteen metal-toligand bonds that lay within the plane of the square, vary between 193 and 198 pm, wheras the remaining eight axial bonds are shorter; they range from 186 to $189 \mathrm{pm}$. This might be compared to simple $\left[\mathrm{Fe}(\text { terpy })_{2}\right]^{2+}$, for which also a compression of the axial $\mathrm{Fe}-\mathrm{N}-$ bonds has been reported. ${ }^{[26]}$ The configuration of the metal ions could be determined by correlation ${ }^{[27]}$ to the stereocentres of the antimonyl tartrate anions $\left(2 R, 2^{6} R, 3 R, 3^{6} R\right)$ - $\left[\mathrm{Sb}_{2} \mathrm{tart}_{2}\right]^{2-}$ and it was found to be $\vec{\Lambda}$. This attribution was confirmed by the determination of the absolute structure of the crystal: The Flack-parameter ${ }^{[28]}$ for the structure containing the $\vec{\Lambda}$-complex cation and $(R, R)$-tartrate converged to $x=-0.01[1]$.

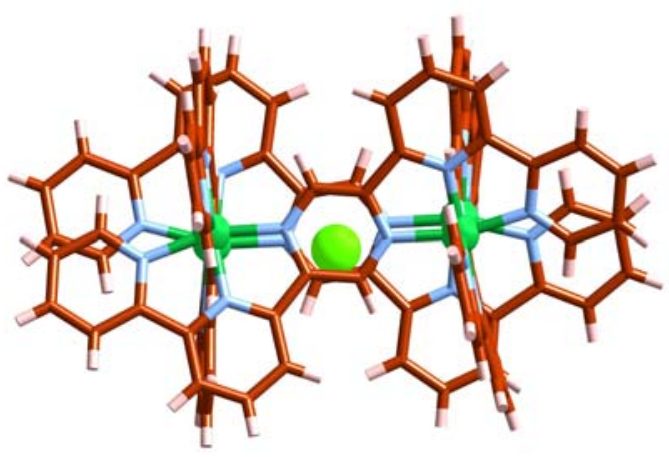

Figure 9: Side view onto the complex cation, stressing the confinement of on chloride anion.

Diastereoselective complex formation An alternative strategy towards stereochemically pure metal complexes, as compared to racemate resolution, lies in the transfer of chirality from a chiral ligand to the metal centre. We applied this diastereoselective approach on the synthesis of such iron square complexes. Ligand L2 is a "chiralised "version of $\mathbf{L} \mathbf{1}$, bearing pinene fragments on the lateral pyridine rings, at the positions 4 " and 5 " (fig. 2).

This ligand was reacted wih $\left[\mathrm{Fe}\left(\mathrm{H}_{2} \mathrm{O}\right)_{6}\right]\left(\mathrm{BF}_{4}\right)_{2}$ as above in the microwave oven. The hexafluorophosphate of the new complex was characterised by ESI-MS (which indicated its tetranuclearity), optical (fig. 10) and NMR spectroscopy. The latter revealed the complete diastereoselectivity of the complexation reaction (within experimental errors); in the related zinc-case, a d.r. of 95:5 was observed. The UV-Vis-spectrum of $\left[\mathrm{Fe}_{4} \mathbf{L} \mathbf{2}_{4}\right]\left(\mathrm{PF}_{6}\right)_{8}$ is very similar to that one of the complex with $\mathbf{L} \mathbf{1}$, but the mirrored CD-spectrum indicates, that the configuration of the metal centres in $\left[\mathrm{Fe}_{4} \mathbf{L} \mathbf{2}_{4}\right]\left(\mathrm{PF}_{6}\right)_{8}$ is $\vec{\Delta}$. This means that from the two possible diastereomers $\mathbf{E}$ and $\mathbf{F}$ (fig. 11) that one (E) was chosen, where the methyl groups from the pinene moieties point to each other at the corners of the square, and not along the sides. This is the same situation as found in the major diastereomer of $\left[\mathrm{Zn}_{4} \mathbf{L} \mathbf{2}_{4}\right]\left(\mathrm{PF}_{6}\right)_{8}$. It was not possible to grow X-ray-grade crystals of the iron(II)-L2-complex.

\section{Computational Methods}

To confirm experimental configuration assignment, TDDFT calculations for circular dichroism (CD) spectrum of $\left[\mathrm{Fe}_{4} \mathbf{L 1}_{4}\right]\left(\mathrm{PF}_{6}\right)_{8}$ have been performed. TDDFT has been recently shown to be well suited for calculation 


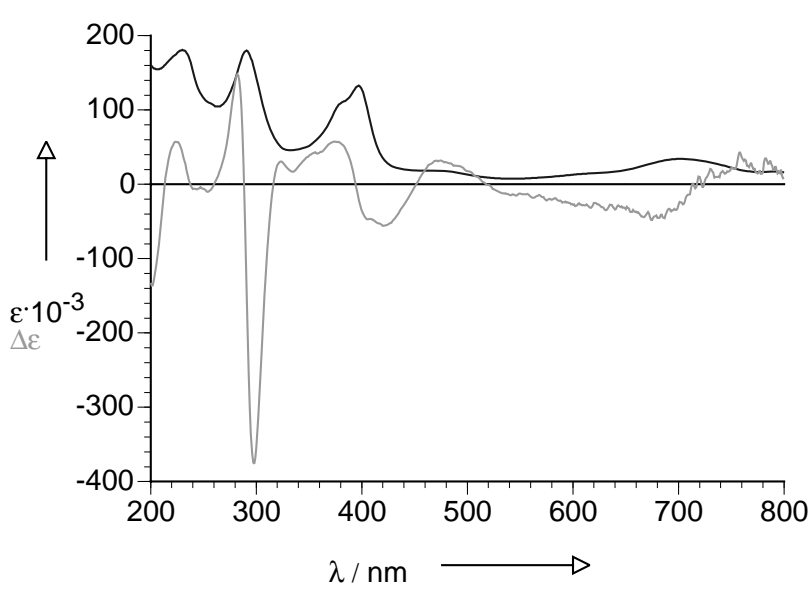

Figure 10: Optical properties of $\left(\vec{\Delta}_{4}\right)-\left[\mathrm{Fe}_{4} \mathbf{L} \mathbf{2}_{4}\right]\left(\mathrm{PF}_{6}\right)_{8}$. Black: UV-Vis-, Grey: CD-spectrum.

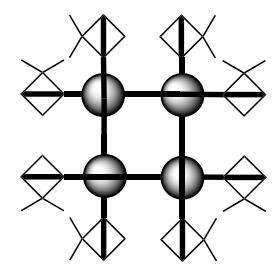

(all- $\vec{\Delta})$

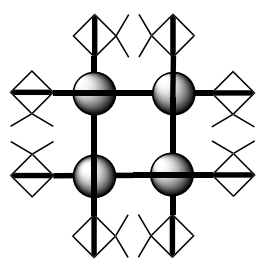

$($ all- $\overrightarrow{-})$
E

$\mathbf{F}$

Figure 11: The two imaginable diastereomers of $\left[\mathrm{Fe}_{4} \mathbf{L 2}_{4}\right]\left(\mathrm{PF}_{6}\right)_{8} . \mathbf{E}$ is the actually formed one.

of CD spectra of simple transition metal complexes ${ }^{[39]}$ and is currently the only ab initio approach capable of treating systems of this size. A large number of electronic excitations of different origin is observed in the calculated spectrum comprising more than 100 allowed transitions in the visible region. The high charge of $\left[\mathrm{Fe}_{4} \mathbf{L} \mathbf{1}_{4}\right]^{8+}$ and the resulting strong interaction with counter-ions and solvent molecules, which is difficult to describe theoretically, is yet another source of error. Six inert $\mathrm{PF}_{6}^{-}$ions were therefore included in the calculations to account for these interactions and to partly compensate the charge of the cation. The calculated CD spectrum of $\left\{\left[\mathrm{Fe}_{4} \mathbf{L 1}_{4}\right]\left(\mathrm{PF}_{6}\right)_{6}\right\}^{2+}$ in the range up to 3 $\mathrm{eV}$ is shown in Figure 12 along with the experimental spectrum. Uniform line width of $0.1 \mathrm{eV}$ was chosen to simulate line broadening. The TDDFT method is known to underestimate excitation energies by some tenth $\mathrm{eV}$ with BP86 functional. Therefore, a blue-shift of $0.2 \mathrm{eV}$ was applied to the calculated CD spectrum to account for these systematic errors and for the lacking solvation effects. Above $2.8 \mathrm{eV}$ a very dense spectrum of electronic excitations appears in which cancellation of large rotatory strengths of opposite sign takes place. Some

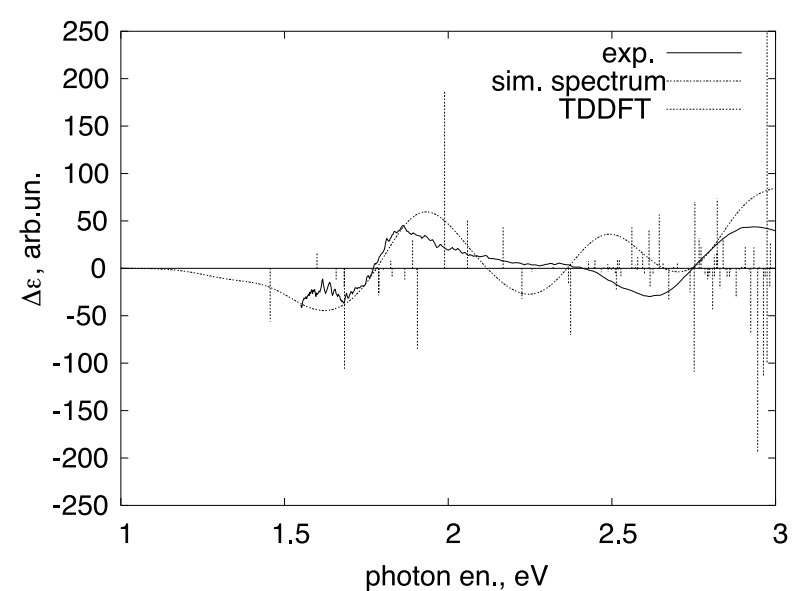

Figure 12: Found and calculated CD spectra of the enantiopure complex $\left[\mathrm{Fe}_{4} \mathbf{L 1}_{4}\right]\left(\mathrm{PF}_{6}\right)_{8}$. For the calculated structure, $\vec{\Lambda}$-configuration of the metal centres was assumed.

of these strong excitations arise from charge-transfer transitions from the $\mathrm{PF}_{6}^{-}$anions and represent clearly artifacts of the calculation. For these reasons only the low-energy region $<3 \mathrm{eV}$ was used for configuration assignment where these exciplex transitions have only little effect on the appearance of the CD spectrum. The strongest electronic excitations of this region are collected in table 1 . The CD spectrum is dominated by charge-transfer excitations from metal $\mathrm{d}$ orbitals into $\pi^{*}$ orbitals of the ligands (MLCT), though an admixture of $\mathrm{d} \rightarrow \mathrm{d}$ transitions and ligand-metal charge transfer (LMCT) should be noted. Experimental and simulated spectrum show semi-quantitative agreement in the considered range. In particular, the general pattern and the sign changes are correctly predicted, allowing for assignment of experimental CD spectrum to the $\vec{\Lambda}$ isomer of $\left[\mathrm{Fe}_{4} \mathbf{L} \mathbf{1}_{4}\right]\left(\mathrm{PF}_{6}\right)_{8}$.

\section{Experimental Section}

Generalities. For the microwave heating, we used a standard household microwave oven, that is modified ${ }^{[29]}$ in a way that allows to attach a reflux condenser to the heated reaction flask: For this purpose, a $2 \mathrm{~cm}$ hole is drilled into the top of the oven and a brace furnace $(L=10 \mathrm{~cm}$, outer $\varnothing=20 \mathrm{~mm}$, inner $\varnothing=18 \mathrm{~mm}$ ) is attached. Measurements showed no leakage of electromagnetical radiation. The reaction flask in the inner of the oven is then connected via a glass tube with two ground joints to the reflux condenser on the outside. 
Table 1: Electronic excitations of $\left[\mathrm{Fe}_{4} \mathbf{L 1}_{4}\right]\left(\mathrm{PF}_{6}\right)_{8}$ below $3 \mathrm{eV}$ with rotatory strengths $>0.5 \cdot 10^{-38} \mathrm{erg} \cdot \mathrm{cm}^{3}$

\begin{tabular}{|cccc|}
\hline Excitation & $\begin{array}{c}\text { Exc. energy } \\
{[\mathrm{eV}]}\end{array}$ & $\begin{array}{c}\text { Rot. strength } \\
10^{-38} \mathrm{erg} \cdot \mathrm{cm}^{3}\end{array}$ & Interpretation \\
\hline $1^{1} A_{2}$ & 1.36 & -0.56 & MLCT \\
$3^{1} E$ & 1.58 & -1.05 & MLCT \\
$6{ }^{1} A_{2}$ & 1.81 & -0.87 & MLCT, $\rightarrow \mathrm{d}$ \\
$10^{1} E$ & 1.88 & 1.88 & $\mathrm{~d} \rightarrow \mathrm{d}$ \\
$11^{1} E$ & 1.96 & 0.52 & $\pi \rightarrow \pi^{*}$, MLCT \\
$16^{1} E$ & 2.27 & -0.70 & MLCT \\
$33^{1} E$ & 2.54 & 0.57 & MLCT \\
$21^{1} A_{2}$ & 2.65 & 0.70 & $\pi \rightarrow \pi^{*}$, LMCT \\
$39^{1} E$ & 2.65 & -1.09 & exciplex \\
$26^{1} A_{2}$ & 2.72 & 0.73 & MLCT, LMCT \\
$59^{1} E$ & 2.82 & -0.67 & MLCT \\
$60^{1} E$ & 2.84 & -1.94 & exciplex \\
$61^{1} E$ & 2.86 & -1.13 & exciplex, MLCT \\
$63^{1} E$ & 2.87 & -0.99 & MLCT \\
$35^{1} A_{2}$ & 2.87 & 6.00 & exciplex \\
\hline
\end{tabular}

NMR-spectra have been recorded on Bruker Varian 400 and 500. UV-Vis- and CD-spectra have been measured on a Perkin Elmer Lambda 25 and Jasco J715, respectively. FT-ESI-MS measurements have been performed on a Bruker BioAPEX II apparatus.

$\mathrm{Fe}\left(\mathrm{BF}_{4}\right)_{2} \cdot \mathrm{xH}_{2} \mathrm{O}$ was purchased from Aldrich. In order to determine the actual iron content, an aliquot of it was reduced with $\mathrm{Zn}$ powder and $\mathrm{HCl}$, before it was titrated with $\mathrm{KMnO}_{4}$. The syntheses of $\mathbf{L} \mathbf{1}$ and $\mathbf{L} \mathbf{2}$ have been described elsewhere. ${ }^{[15]}$

Synthesis of (rac)- $\left[\mathrm{Fe}_{4} \mathbf{L 1}_{4}\right]\left(\mathrm{PF}_{6}\right)_{8} \cdot \mathrm{Fe}\left(\mathrm{BF}_{4}\right)_{2} \cdot \mathrm{x} \mathrm{H}_{2} \mathrm{O}$ $(280.9 \mu \mathrm{mol})$ is placed in a $250 \mathrm{ml}$-flask and is dissolved in 3 $\mathrm{ml}$ of 9/1 ethylene glycole/water. L1 $(109.1 \mathrm{mg}, 208.9 \mu \mathrm{mol})$ is added, as well as ascorbic acid $(10 \mathrm{mg})$. The mixture is heated to reflux under argon in a modified microwave oven for 4 minutes. The mixture turns dark green. The cooled mixture is diluted with $\mathrm{MeCN}(3 \mathrm{ml})$ and the complex is precipitated with aqueous $\mathrm{NH}_{4} \mathrm{PF}_{6}(1 \%, 100 \mathrm{ml})$. The complex is filtered off over Celite. It is washed with water and ether and it is air-dried. The compound is washed off with MeCN and is purified by chromatography on a short column (silica 32-64 $\mu \mathrm{m}, \mathrm{MeCN}+1 \%$ sat. aqu. $\mathrm{NH}_{4} \mathrm{PF}_{6}$ ). The complex is isolated from the eluted fraction by precipitation, as it is described above. $208.5 \mathrm{mg}$ (>99\%), black powder.

${ }^{1} \mathrm{H}-\mathrm{NMR}\left(500.13 \mathrm{MHz},\left[\mathrm{D}_{3}\right]-\mathrm{MeCN}\right): 8.96(\mathrm{dd}, J=8.3,0.8$, $\left.2 \mathrm{H}, \mathrm{H}-\mathrm{C}\left(3^{\prime}\right)\right) ; 8.56\left(\mathrm{dd}, J=8.3,8.1,2 \mathrm{H}, \mathrm{H}-\mathrm{C}\left(4^{\prime}\right)\right) ; 8.47$ $(\mathrm{d} \cdot \mathrm{m}, J=8.1,2 \mathrm{H}, \mathrm{H}-\mathrm{C}(3 ")) ; 8.21(\mathrm{dd}, J=8.1,0.6,2 \mathrm{H}$, $\left.\mathrm{H}-\mathrm{C}\left(5^{\prime}\right)\right) ; 7.91$ (ddd, $\left.J=8.2,8.1,1.6,2 \mathrm{H}, \mathrm{H}-\mathrm{C}\left(4^{\prime \prime}\right)\right) ; 7.06$ $(\mathrm{s}, 2 \mathrm{H}, \mathrm{H}-\mathrm{C}(3$ and 5$)) ; 7.02$ (ddd, $J=5.7,1.5,0.7,2 \mathrm{H}$, $\mathrm{H}-\mathrm{C}(6 ")) ; 6.98(\mathrm{td}, J=5.7,1.3,2 \mathrm{H}, \mathrm{H}-\mathrm{C}(5 "))$.

NOE-Diff.: $8.96(8.56,+1.9 \% ; 8.47,+2.7 \%) ; 8.47(8.96$ $+2.6 \%, 7.91,+2.2 \%) ; 8.21(8.56,+2.0 \% ; 7.06,+3.9 \%)$.
${ }^{13} \mathrm{C}-\mathrm{NMR}\left(125.76 \mathrm{MHz},\left[\mathrm{D}_{3}\right]-\mathrm{MeCN}\right): 160.21 \mathrm{q} ; 157.54 \mathrm{q} ;$ 156.84 q; 155.85 q; $154.14\left(\mathrm{C}\left(6^{\prime \prime}\right)\right) ; 146.20(\mathrm{C}(3)) ; 140.92$ $\left(\mathrm{C}\left(4^{\prime \prime}\right)\right) ; \quad 139.31\left(\mathrm{C}\left(4^{\prime}\right)\right) ; 128.76\left(\mathrm{C}\left(5^{\prime \prime}\right)\right) ; 128.18 \quad\left(\mathrm{C}\left(5^{\prime}\right)\right)$; $126.65\left(\mathrm{C}\left(3^{\prime}\right)\right) ; 125.85\left(\mathrm{C}\left(3^{\prime \prime}\right)\right)$.

ESI-MS (MeCN): $1326 \quad\left(72 \%, \quad\left\{\left[\mathrm{Fe}_{4} \mathbf{L 1}_{4}\right]\left(\mathrm{PF}_{6}\right)_{6}\right\}^{2+}\right)$; $834 \quad\left(100 \%, \quad\left\{\left[\mathrm{Fe}_{4} \mathbf{L 1}_{4}\right]\left(\mathrm{PF}_{6}\right)_{5}\right\}^{3+}\right) ; \quad 589 \quad(43 \%$, $\left.\left\{\left[\mathrm{Fe}_{4} \mathbf{L} \mathbf{1}_{4}\right]\left(\mathrm{PF}_{6}\right)_{4}\right\}^{4+}\right) ; \quad 442\left(13 \%, \quad\left\{\left[\mathrm{Fe}_{4} \mathbf{L} \mathbf{1}_{4}\right]\left(\mathrm{PF}_{6}\right)_{3}\right\}^{5+}\right)$; $413\left(6 \%,\left\{\left[\mathrm{Fe}_{4} \mathbf{L} \mathbf{1}_{4}\right]\left(\mathrm{PF}_{6}\right)_{2}+1 \mathrm{e}^{-}\right\}^{5+}\right)$.

High resolution ESI-MS $(\mathrm{MeCN}):\left\{\left[\mathrm{Fe}_{4} \mathbf{L 1}_{4}\right]\left(\mathrm{PF}_{6}\right)_{5}\right\}^{3+}$, $\mathrm{C}_{96} \mathrm{H}_{64}{ }^{56} \mathrm{Fe}_{4} \mathrm{~F}_{30} \mathrm{~N}_{24} \mathrm{P}_{5}$ requires: 833.7115210; found: 833.7112016; error: $3.194 \cdot 10^{-4}$.

Resolution of (rac)-[ $\left.\mathrm{Fe}_{4} \mathbf{L 1}_{4}\right]\left(\mathrm{PF}_{6}\right)_{8}$. The complex $(52.8 \mathrm{mg}, 18.0 \mu \mathrm{mol})$ is dissolved in $\mathrm{MeNO}_{2}(4 \mathrm{ml})$ and a solution of $\mathrm{NBu}_{4} \mathrm{Cl}(400 \mathrm{mg}, 1.44 \mathrm{mmol})$ in $\mathrm{MeNO}_{2}(4 \mathrm{ml})$ is added. $\left[\mathrm{Fe}_{4} \mathbf{L 1}_{4}\right] \mathrm{Cl}_{8}$ precipitates and is isolated by centrifugation. The product is washed several times with EtOAc, then with ether. To the filtered solution of this chloride salt in water $(0.8 \mathrm{ml})$, a solution of " $\mathrm{KSb}$ (tartrate) $\cdot 3 \mathrm{H}_{2} \mathrm{O}$ " $(16.1 \mathrm{mg}, 52$ $\mu \mathrm{mol})$ in water $(0.8 \mathrm{ml})$ is added. If available, some seeding crystals are added. The mixture is kept at room temperature for 24 hours, followed by another 24 hours at $4{ }^{\circ} \mathrm{C}$. The resolved complex crystallised in dark, brick-shaped crystals (if an amorphous powder is obtained instead, the resolution procedure has failed). The mother liquor is removed and the crystals are washed with little cold water. They are dissolved in water $(30 \mathrm{ml})$ and $\mathrm{NH}_{4} \mathrm{PF}_{6}(300 \mathrm{mg})$ is added. The precipitated hexafluorophosphate salt is filtered off over Celite. It is washed with water and ether and it is air-dried. $14.6 \mathrm{mg}$ (55 $\%)$.

UV-Vis $\left(\lambda_{\max }(\epsilon), \mathrm{MeCN}, c=5.52 \cdot 10^{-6} \mathrm{~mol} \cdot \mathrm{l}^{-1}, L=\right.$ $1 \mathrm{~cm}): 283 \mathrm{~nm}\left(9.53 \cdot 10^{4} \mathrm{~mol} \cdot \mathrm{l}^{-1} \cdot \mathrm{cm}^{-1}\right) ; 368 \mathrm{sh}\left(8.42 \cdot 10^{4}\right)$; $386\left(1.17 \cdot 10^{5}\right) ; 682\left(2.79 \cdot 10^{4}\right)$. 
$\mathrm{CD}\left(\lambda_{\min / \max }(\Delta \epsilon), \mathrm{MeCN}, c=5.52 \cdot 10^{-6} \mathrm{~mol} \cdot \mathrm{l}^{-1}, L=\right.$ $1 \mathrm{~cm}): 261 \mathrm{~nm}\left(23.4 \mathrm{~mol} \cdot \mathrm{l}^{-1} \cdot \mathrm{cm}^{-1}\right) ; 279(-150) ; 293(254)$; $362(-89.9) ; 386(117) ; 422(43.9) ; 474(-29.7) ; 665$ (45); $737(-36)$

Crystallographic analysis of $\left[\mathrm{Fe}_{4} \mathbf{L} \mathbf{1}_{4}\right] \mathrm{Cl}_{2}\left(\mathrm{Sb}_{2} \mathrm{tart}_{2}\right)_{3}$. $\mathrm{C}_{120} \mathrm{H}_{76} \mathrm{Cl}_{2} \mathrm{Fe}_{4} \mathrm{~N}_{24} \mathrm{O}_{36} \mathrm{Sb}_{6} \cdot 54 \mathrm{H}_{2} \mathrm{O}, M_{r}=4427.61$. Dark green plate, crystallised from water, $0.32 \cdot 0.32 \cdot 0.14 \mathrm{~mm}^{3}$, monoclinic, space group $P 2_{1}, Z=2, a=16.3525(5) \AA$ $b=32.9157(8) \AA, c=18.1155(5) \AA, \alpha=\gamma=90^{\circ}, \beta=$ $105.625^{\circ}, V=9390.4 \AA^{3} \cdot \rho_{\text {calc. }}=1566 \mathrm{~kg} \cdot \mathrm{m}^{-3}$. The crystal was measured on a Bruker-Nonius KappaCCD area detector, at $173 \mathrm{~K}$, using graphite-monochromated $\mathrm{MoK} \alpha_{\alpha}$-radiation with $\lambda=0.71073 \AA, 2 \theta_{\max }=57.0^{\circ} . T_{\min }=0.66, T_{\max }=0.84$, $\mu=1.275 \mathrm{~mm}^{-1}$. From a total of 148,457 reflections, 46,022 were independent. From these, 35,471 were considered as observed $(I>3 \sigma(I))$ and were used to refine 2367 parameters. The structure was solved by direct methods. Least-squares refinement against $|F|$ was carried out on all non-hydrogen atoms. $R=0.0486$ (observed data), $w R=0.0516$ (all data) $G O F=1.019$. Minimal $/$ maximal residual electron density $=-3.56 / 3.55 \mathrm{e} \cdot \AA^{-3}$. The Flack-parameter for the chosen absolute structure was $x=0.01(1)$.

60 positions of water-based oxygen atoms have been localised; 33 of which were considered as normally occupied, 8 as disordered and 19 as partially occupied. As the electron density of the remaining maxima of the difference Fourier map decrease continuously, the actual number of water molecules could not be determined precisely. The water protons could not be located. Deposition No. CCDC208876 contains the supplementary crystallographic data for this paper. These data can be obtained, free of charge, via www.ccdc.cam.ac.uk/conts/retrieving.html (or from Cambridge Crystallographic Data Centre, 12 Union Road, Cambridge CB2 1RZ, UK. Fax: (+44) 1223-336-033; or email: deposit@ccdc.cam.ac.uk).

Synthesis $\quad$ of $\quad(\vec{\Delta}, \vec{\Delta}, \vec{\Delta}, \vec{\Delta})-\left[\mathrm{Fe}_{4} \mathbf{L} \mathbf{2}_{4}\right]\left(\mathrm{PF}_{6}\right)_{8}$. $\mathrm{Fe}\left(\mathrm{BF}_{4}\right)_{2} \cdot \mathrm{x} \mathrm{H}_{2} \mathrm{O} \quad(93.3 \mu \mathrm{mol})$ and $\mathbf{L 2} \quad\left(\begin{array}{llll}53.8 & \mathrm{mg}, \quad 93.3\end{array}\right.$ $\mu \mathrm{mol})$ are reacted as described for $($ rac $)-\left[\mathrm{Fe}_{4} \mathbf{L 1}_{4}\right]\left(\mathrm{PF}_{6}\right)_{8}$. $81.2 \mathrm{mg}(94 \%)$ of diasteriomerically pure $(\vec{\Delta}, \vec{\Delta}, \vec{\Delta}, \vec{\Delta})$ $\left[\mathrm{Fe}_{4} \mathbf{L 2}_{4}\right]\left(\mathrm{PF}_{6}\right)_{8}$ are obtaiend after chromatography and precipitation.

${ }^{1} \mathrm{H}-\mathrm{NMR} \quad\left(500.13 \mathrm{MHz}, \quad\left[\mathrm{D}_{3}\right]-\mathrm{MeCN}\right): 8.86(\mathrm{dd}, \quad J=8.3$, $\left.0.8,2 \mathrm{H}, \mathrm{H}-\mathrm{C}\left(3^{\prime}\right)\right) ; 8.51\left(\mathrm{t}, \quad J=8.2,2 \mathrm{H}, \mathrm{H}-\mathrm{C}\left(4^{\prime}\right)\right) ; 8.28$ $(\mathrm{s}, 2 \mathrm{H}, \mathrm{H}-\mathrm{C}(3 / 5)) ; 8.13\left(\mathrm{dd}, J=8.2,0.8,2 \mathrm{H}, \mathrm{H}-\mathrm{C}\left(5^{\prime}\right)\right)$; $7.02\left(\mathrm{~s}, 2 \mathrm{H}, \mathrm{H}-\mathrm{C}\left(3^{\prime \prime}\right)\right) ; 6.45\left(\mathrm{~s}, 2 \mathrm{H}, \mathrm{H}-\mathrm{C}\left(6^{\prime \prime}\right)\right) ; 2.99(\mathrm{~m}, 4 \mathrm{H}$, $\left.\mathrm{H}_{\text {pro }-\mathrm{R}} \mathrm{H}_{\text {pro }-\mathrm{S}} \mathrm{C}\left(7^{\prime \prime}\right)\right) ; 2.33\left(\mathrm{dt}, J=9.9,5.8,2 \mathrm{H}, \mathrm{H}_{\text {pro }-\mathrm{S}^{-}}\right.$ $\mathrm{C}(11)) ; 2.26(\mathrm{t}, J=5.5,2 \mathrm{H}, \mathrm{H}-\mathrm{C}(10 ")) ; 2.10$ (ddd, $J=8.2$, 5.6, 2.6, $\left.2 \mathrm{H}, \mathrm{H}-\mathrm{C}\left(8^{\prime \prime}\right)\right) ; 1.08$ (s, $\left.6 \mathrm{H}, \mathrm{Me}(13 ")\right)$; 0.59 (d, $J=$ $\left.10.0,2 \mathrm{H}, \mathrm{H}_{\text {pro- }-\mathrm{R}}-\mathrm{C}(11 ")\right)$; 0.02 (s, $\left.6 \mathrm{H}, \mathrm{Me}(12 ")\right)$.

${ }^{13} \mathrm{C}-\mathrm{NMR}\left(125.76 \mathrm{MHz},\left[\mathrm{D}_{3}\right]-\mathrm{MeCN}\right): 160.58 \mathrm{q} ; 156.25 \mathrm{q} ;$ 155.85 q; 155.19 q; 150.76 q; 149.21 q; 148.36 (C(6”)); 145.65 (C(3”)); $139.09\left(\mathrm{C}\left(4^{\prime}\right)\right) ; 127.30\left(\mathrm{C}\left(5^{\prime}\right)\right) ; 125.86\left(\mathrm{C}\left(3^{\prime}\right)\right) ; 125.26$ $(\mathrm{C}(3 / 5)) ; 44.70\left(\mathrm{C}\left(10^{\prime \prime}\right)\right) ; 39.88\left(\mathrm{C}\left(8^{\prime \prime}\right)\right) ; 38.98$ (q, C(9")); $33.41\left(\mathrm{C}\left(7^{\prime \prime}\right)\right) ; 30.50(\mathrm{C}(11 ")) ; 25.25(\mathrm{C}(13)) ; 20.74(\mathrm{C}(12))$.
ESI-MS $\quad(\mathrm{MeCN}): \quad 1700 \quad\left(11 \%, \quad\left\{\left[\mathrm{Fe}_{4} \mathbf{L 2}_{4}\right]\left(\mathrm{PF}_{6}\right)_{6}\right\}^{2+}\right.$; $1085 \quad\left(27 \%, \quad\left\{\left[\mathrm{Fe}_{4} \mathbf{L} \mathbf{2}_{4}\right]\left(\mathrm{PF}_{6}\right)_{5}\right\}^{3+} ; \quad 778 \quad(76 \%\right.$, $\left\{\left[\mathrm{Fe}_{4} \mathbf{L 2}_{4}\right]\left(\mathrm{PF}_{6}\right)_{4}\right\}^{4+} ; \quad 593 \quad\left(100 \%, \quad\left\{\left[\mathrm{Fe}_{4} \mathbf{L 2}_{4}\right]\left(\mathrm{PF}_{6}\right)_{3}\right\}^{5+}\right.$; $564\left(\%,\left\{\left[\mathrm{Fe}_{4} \mathbf{L 2}_{4}\right]\left(\mathrm{PF}_{6}\right)_{2}+\mathrm{e}^{-}\right\}^{5+}\right.$.

$470\left(95 \%,\left\{\left[\mathrm{Fe}_{4} \mathbf{L 2}_{4}\right]\left(\mathrm{PF}_{6}\right)_{2}\right\}^{6+}\right.$.

High resolution ESI-MS $(\mathrm{MeCN}): \quad\left\{\left[\mathrm{Fe}_{4} \mathbf{L 2}_{4}\right]\left(\mathrm{PF}_{6}\right)_{5}\right\}^{3+}$, $\mathrm{C}_{152} \mathrm{H}_{144} \mathrm{~F}_{30}{ }^{56} \mathrm{Fe}_{4} \mathrm{~N}_{24} \mathrm{P}_{5}$ requires: 1084.5865357; found: 1084.5865290; error: $6.7 \cdot 10^{-6}$.

UV-Vis $\left(\lambda_{\max }(\epsilon), \mathrm{MeCN}, c=4.89 \cdot 10^{-6} \mathrm{~mol} \cdot 1^{-1}, L=1 \mathrm{~cm}\right)$ : $232\left(1.80 \cdot 10^{5}\right) ; 291\left(1.80 \cdot 10^{5}\right) ; 382\left(1.10 \cdot 10^{5}\right) ; 397\left(1.33 \cdot 10^{5}\right)$; $480\left(1.79 \cdot 10^{4}\right) ; 702\left(3.42 \cdot 10^{4}\right)$.

$\mathrm{CD}\left(\lambda_{\min / \max }(\Delta \epsilon), \mathrm{MeCN}, c=4.89 \cdot 10^{-6} \mathrm{~mol} \cdot \mathrm{l}^{-1}\right.$, $L=1 \mathrm{~cm}): 224(57) ; 254(-10) ; 282(148) ; 298(-376)$; 323 (31); 334 (min.,17); 375 (57); 421 (-55); 474 (32); $674\left(-5 \cdot 10^{2}\right) ; 758\left(6 \cdot 10^{2}\right)$.

Computational details All calculations were performed within the framework of density functional theory (DFT) employing gradient-corrected BP86 functional. ${ }^{[30,31]}$ We used split-valence basis set with polarization functions on nonhydrogen atoms $\left(\mathrm{SV}(\mathrm{P})^{[32]}\right)$ together with efficient RI- $J$ approximation for Coulomb matrix elements. ${ }^{[33]}$ The ground state geometry of .1. was fully optimized within $D_{4}$ symmetry. For the optimized structure electronic excitation energies and corresponding rotatory strengths were calculated with timedependent density functional theory (TDDFT). ${ }^{[34,35,36]} \mathrm{In}$ terpretation of character of electronic transitions is based on the analysis of excitation vectors. ${ }^{[37]}$ The Turbomole ${ }^{[38]}$ program suite was used for all calculations.

\section{References}

[1] M. Fujita, J. Yazaki, K. Ogura, J. Am. Chem. Soc. 1990, 112, 5645-5647.

[2] M. Fujita, J. Yazaki, K. Ogura, Chem. Lett. 1991, 1031-1032.

[3] T. Damhus, C. E. Schäffer, Inorg. Chem. 1983, 22, 2406-2412.

[4] A. von Zelewsky, Stereochemistry of Coordination Compounds, John Wiley \& Sons, Chichester, UK, 1995, p. 70.

[5] M. T. Youinou, N. Rahmouni, J. Fischer, J. A. Osborn, Angew. Chem., Int. Ed. Engl. 1992, 31, 733735 .

[6] M. Ruben, E. Breuning, M. Barboiu, J.-P. Gisselbrecht, J.-M. Lehn, Chem.- Eur. J. 2003, 9, 291299.

[7] J. R. Galan-Mascaros, K. R. Dunbar, Chem. Commun. 2001, 217-218. 
[8] H. Grove, J. Sletten, M. Julve, F. Lloret, J. Cano, J. Chem. Soc., Dalton Trans. 2001, 259-265.

[9] N. D. Sung, K. S. Yun, T. Y. Kim, K. Y. Choi, M. Suh, J. G. Kim, I. H. Suh, J. Chin, Inorg. Chem. Comm. 2001, 4, 377-380.

[10] R. Krämer, L. Kovbasyuk, H. Pritzkow, New J. Chem. 2002, 26, 516-518.

[11] J. P. Plante, P. D. Jones, D. R. Powell, T. E. Glass, Chem. Commun. 2003, 336-337.

[12] D. M. Bassani, J.-M. Lehn, K. Fromm, D. Fenske, Angew. Chem., Int. Ed. 1998, 37, 2364-2367.

[13] C. S. Campos-Fernandez, R. Clerac, K. R. Dunbar, Angew. Chem., Int. Ed. 1999, 38, 3477-3479.

[14] X.-H. Bu, M. Hiromasa, K. Tanaka, K. Biradha, S. Furusho, M. Shionoya, Chem. Commun. 2000, $971-972$.

[15] T. Bark, H. Stoeckli-Evans, A. von Zelewsky, J. Chem. Soc., Perkin Trans. 1 2002, 1881-1886.

[16] T. Bark, M. Düggeli, H. Stoeckli-Evans, A. Von Zelewsky, Angew. Chem., Int. Ed. 2001, 40.

[17] A. von Zelewsky, O. Mamula, J. Chem. Soc., Dalton Trans. 2000, 219-231.

[18] E. Breuning, G. S. Hanan, F. J. Romero-Salguero, A. M. Garcia, P. N. W. Baxter, J.-M. Lehn, E. Wegelius, K. Rissanen, H. Nierengarten, A. Van Dorsselaer, Chem.-Eur. J. 2002, 8, 3458-3466.

[19] A. Neels, H. Stoeckli-Evans, Inorg. Chem. 1999, 38, 6164- 6170 .

[20] C. S. Campos-Fernandez, R. Clerac, J. M. Koomen, D. H. Russell, K. R. Dunbar, J. Am. Chem. Soc. 2001, 123, 773-774.

[21] M. Ziegler, A. Von Zelewsky, Coord. Chem. Rev. 1998, 177, 257-300.

[22] J. Lacour, C. Ginglinger, C. Grivet, G. Bernardinelli, Angew. Chem., Int. Ed. 1997, 36, 608-609.

[23] J. Lacour, V. Hebbe-Viton, Chem. Soc. Rev. 2003 32, 373-382, and references therein.

[24] H.-C. Mu, Kexue Tongbao (Chinese Ed.) 1966, 17, 502-504, Chem. Abstr. Serv., 1967:69731.

[25] M. E. Gress, R. A. Jacobson, Inorg. Chim. Acta 1974, 8, 209-217.

[26] A. T. Baker, H. A. Goodwin, Austr. J. Chem. 1985, 38, 207-214.
[27] A. Zalkin, D. H. Templeton, T. Ueki, Inorg. Chem. 1973, 12, 1641-1646.

[28] H. D. Flack, Acta Cryst. 1983, A39, 876-881.

[29] E. Jandrasics, PhD thesis Nr. 1085, University of Fribourg (Switzerland), Faculty of Science, 1995.

[30] A. D. Becke, Phys. Rev. A 1988, 38, 3098-3100.

[31] J. P. Perdew, W. Yue, Phys. Rev. B 1986, 33, 88008802.

[32] A. Schäfer, H. Horn, R. Ahlrichs J. Chem. Phys. 1992, 97, 2571-2571.

[33] K. Eichkorn, O. Treutler, H. Öhm, M. Häser, R. Ahlrichs, Chem. Phys. Lett. 1995, 240, 283-289.

[34] M. E. Casida in Recent Advances in Density Functional Methods (Ed.: D. P. Chong), World Scientific, Singapore, 1995, p. 155.

[35] R. Bauernschmitt, R. Ahlrichs, Chem. Phys. Lett. 1996, 256, 454-464.

[36] R. Bauernschmitt, M. Häser, O. Treutler, R. Ahlrichs, Chem. Phys. Lett. 1997, 264, 573-578.

[37] F. Furche, R. Ahlrichs, C. Wachsmann, E. Weber, A. Sobanski, F. Vögtle, S. Grimme, J. Am. Chem. Soc. 2000, 122, 1717-1724.

[38] R. Ahlrichs, M. Bär, M. Häser, H. Horn, C. Kölmel, Chem. Phys. Lett. 1989, 162, 165-169, also see http://www.turbomole.de.

[39] J. Autschbach, F. E. Jorge, T. Ziegler, Inorg. Chem. 2003, 42, 2867-2877.

\section{Acknowledgement}

This work is financially supported by the Swiss National Science Foundation.

We thank Mr. Ivan Schindelholz for the synthesis of ligand L1 and Mr. Freddy Nydegger for recording MS spectra. D.R. thanks Prof. R. Ahlrichs and Dr. F. Furche for support and valuable discussions. 